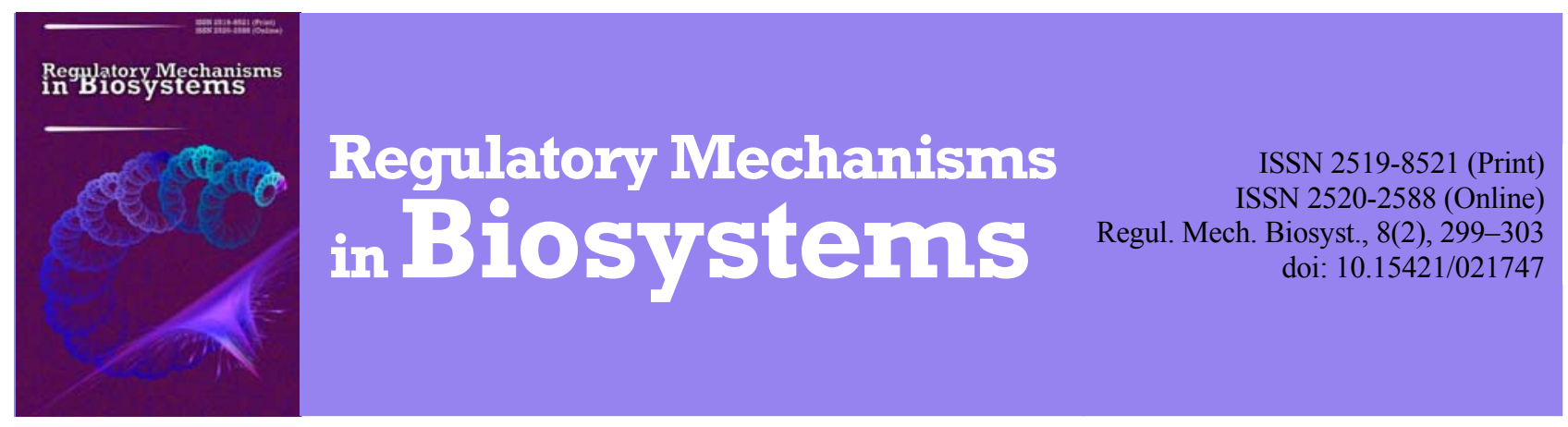

\title{
The quality of colostrum and vitality of calves, born from cows with different reaction to stress experiences
}

\author{
O. M. Chernenko, O. I. Chernenko, R. A. Sanjara \\ Dnipro State Agrarian-Economic University, Dnipro, Ukraine
}

Article info

Received 02.04.2017

Received in revised form 25.04.2017

Accepted 29.04.2017

Dnipro State

Agrarian-Economic University,

Sergey Efremov Str., 25,

Dnipro, 49600, Ukraine.

Tel.:+38-056-713-51-74

E-mail: chernenko_an@ukr.net

\begin{abstract}
Chernenko, A. N., Chernenko, E. I., \& Sanjara, R. A. (2017). The quality of colostrum and vitality of calves, born from cows with different reaction to stress experiences. Regulatory Mechanisms in Biosystems, 8(2), $299-303$. doi:10.15421/021747
\end{abstract}

The article presents the results of studying cortisol concentration and creatine phosphokinase activity in the blood serum of 40 half-sib Ukrainian black and white dairy cows an hour after planned blood extraction, which was a stress experience. We divided the cows into three groups according to the distribution of cortisol concentration in the animals: I - high, II - average and III - low stress resistance. During the research, the cows from these groups were in their fourth month of lactation after their first calving. They were kept untethered in their summer quarters, natural pastures. The aim of the research was to identify the differences in the quality of colostrum, the vitality of the calves up to the age of 6 months, the vitality of the mother-cows, and also the influence of their different adaptation potentials in cases of abortion and stillborn calves among the cows from different groups. At the dairy complex where the research was conducted, the quality of the cows' colostrum is not monitored. This is typical for most dairy plants of Ukraine. We found that the classes of $\mathrm{A}$ and $\mathrm{M}$ immunoglobulins did not depend upon which particular groups the animals belonged to, whereas the content of immunoglobulins of class $\mathrm{G}$ is $6.7 \mathrm{~g} / \mathrm{l}$ higher, and the content of total protein is $8.9 \mathrm{~g} / \mathrm{l} \mathrm{higher}$ in the yield of colostrum of the cows from group 1. The influence of cows' different levels of resistance to stress experiences on their incidence of abortions and stillborn calves was not determined. Gastroenteritis occurred among calves of cows from group 3 three times more often than with those of group 1. Vitality of calves from cows of groups 1 and 2 was significantly higher. Therefore, technological stress experiences of mother-cows have a negative effect upon the quality of colostrum and upon the vitality of calves. This factor ought to be taken into consideration in the exploitation of animals, especially during pregnancy in order to minimise stress and help individuals with less strong nervous systems. Solving the complex problems of increasing the vitality of calves involves in part guaranteeing their provision with colostrum immunity by compulsory control of the colostrum' quality using a special aerometer (Colostrometer).

Keywords: cortisol; creatine phosphokinase; adaptation potential; immunoglobulins A and M; content of protein

\section{Introduction}

It is proven that stress decreases immunity (Roth et al., 1985; Frank et al., 1989; Moberg et al., 2000; Salak-Johnson et al., 2006; Carroll et al., 2013). Stress which leads to "disruption" of immunity, misbalances the organism with the environment (Hansen et al., 1998; Chernenko, 2015a). This leads to disorders of homeostasis (Friend et al., 1977; Friend et al., 1980). It is well understood (Lefcourt et al., 1982; Borell et al., 2007) that different animals react differently to the same stress factor. Some are able to quickly adapt, whereas others adapt much slower or are unable to overcome the stress. The reason for this may be different biological adequacies of the organism, for some animals can be obtained using inbreeding, and others using outbreeding (Hansen et al., 2002). Also the temperament and the behaviour of animals are inherited (Salak-Johnson et al., 2006). Homeostasis of some individuals recovers significantly faster, without occurrence of any negative effects on health, rapid decrease in productivity and reproductive capacity (Beilharz et al., 1982; Borell et al., 2007; Chernenko, 2015b). For others, the same stress-factors cause devastating consequences and homeostasis does not regenerate for a long time (Wolfenson et al., 2000).

Recovering the stability of an organism's internal environment requires significant additional energetic resources (Giesecke et al.,
1985). The organism has to obtain them, first of all, using its own reserves. In particular, this is achieved through the process of gluconeogenesis. However, this is impossible without "building material" in the form of free amino acids and fatty acids. Therefore stress hormones, especially cortisol, block the synthesis of protein and fats (Giesecke et al., 1985). This is a part of the so-called general adaptation syndrome (GAS). The efficiency of an organism's recovery depends upon the duration of influence of a stress-factor (Frank et al., 1989), the intensity of stress-factors (Lacetera et al., 2001), and also upon the individual adaptation capacities of the organism (Salak-Johnson et al., 2006). Stress can lead to significant lactational fluctuations (Gorewit et al., 1992; Wenzel et al., 2003), can endanger the antimicrobial efficiency of natural protection mechanisms of the udder and increase the risk of non-physiological regression of mammary gland, and cause subclinical and clinical mastitogen infections of the udder (Giesecke et al., 1985). There are also reports of decrease of Luteinizing hormone secretion in cases of chronic stress (Borell et al., 2007).

There is data that heat stress can lead to decrease in the content of total protein, casein, lactalbumin, fat and lactose in the colostrum, and increase pH (Frank et al., 1989; Nardone et al., 1997). The process of calving is the most severe form of stress for a cow's organism. Taking calves away practically after they are born is stress both for them and 
for mothers. However, there is data (Hickey et al., 2002) that the cows overcome this process with a minmum of stress. But do all of them? Colostrum is not only the first food for newborn calves, but also a source of immunoglobulins. Ig provides the collostrum immunity. The colostrum contain also antimicrobial components: lactoferrin, lysozyme and lactoperoxidase (Pakkanen et al., 1997). Also colostrum contain hormones, growth factors, cytokine, enzymes, polyamins and nucleotides, which have a significant biological effect upon newborn calves (Blum et al., 2000). Despite that, there is data that newborn calves' intestines have no activity of selecting immunoglobulins (Besser et al., 1985), and that the amount of Ig in a calf's blood does not depend on the amount of colostrum obtained by a calf, although the colostrum does contain a certain minimum or norm of $\operatorname{Ig}$ (Bush et al., 1980). Colostrum with Ig content below this norm are considered inadmissible for milk feeding (Morin et al., 2001). Therefore the quality of colostrum is controlled using an areometer (Colostrometer). However, in Ukraine this is a rare case - only on best particular plants. Most plants do not take such control seriously. The quality of milk is also conditioned by the breed (Muller et al., 1981), the month of calving (Morin et al., 2001), mastitis (Maunsell et al., 1998) and other factors.

In this context, we should highlight that vitality of calves in modern conditions of intense production technology is still maintained at an insufficient level. Prenatal and postnatal losses negatively affect the speed and quality of a herd's recovery as well as the economic indicators of livestock rearing. Therefore the problem requires a complex solution, for the vitality of calvesy is affected by different factors. It is known that (Monty et al., 1987; Hansen et al., 2002) prenatal losses occur due to internal defects of the embryo, inadequate maternal environment, asynchronous interaction of embryo and the mother, or due to mother's inability to adequately react to embryonic signals. The pre-implantational embryo is most sensitive to certain types of stress at very early stage of development (embryo stress). There is data (Tao et al., 2012), that stress leads to disorders of immunity among cows and newborn calves, and there is also a presumption that it can endanger their vitality from birth to weaning. Stress decreases libido and embryonic vitality of cattle. In particular, heat stress in the final months of pregnancy decreases the growth of the fetus, changes the endocrine status of mother-cows and leads to decrease in general metabolism (Collier et al., 1982; Wolfenson et al., 2000). One limiting factor is the inability of cows with high milk performance to maintain normothermia (Wolfenson et al., 2000). This occurs because higher milk performance is connected with a great exit of heat form the organism of cows (Igono et al., 2008). The amount of immunoglobulin in the blood of newborn calves depends on the quality of the colostrum. Robison et al. (1988) found that the mortality was $6.8 \%$ among calves with less than $12 \mathrm{mg} / \mathrm{ml}$ of serum Ig 24-48 hours after birth, compared to other calves of the same age with Ig concentration in the blood higher than $12 \mathrm{mg} / \mathrm{ml}(3.3 \%$ mortality). Merlot et al. (2013) defined that stress weakens the immune system of mother-cows and damages their health; this can influence the transfer of pathogens to the fetus. Calves born from cows with dystonia died five times more often during the neonatal period than calves born without any assistance. Among all the calves that died, $43.6 \%$ were born with difficulties. Among these calves, the vitality was the lowest among those who had the smallest body mass (Azzam et al., 2017). Similar results have been obtained by other researchers (Tenhagen et al., 2007).

The following hypotheses are proposed in relation to this. The varying stability of different organisms to different stress experiences is possibly affected by the compound of cows' colostrum. High and low stability to technogenic stresses among mother-cows possibly influences the occurrence of abortions and cases of stillbirth of calves, and also the vitality of calves after birth and the vitality of mother-cows.

The aim of this research is to assess the influence of the adaptive potential of cows on their colostrum and the vitality of calves in conditions of industrial farming, where stress experiences occur frequently due to regrouping of animals, changes in technological regimes of maintenance during summer and winter periods, taking the calves from their mothers at early stage, veterinary services, etc.

\section{Materials and methods}

The research was conducted using half-sib cows of the Ukrainian black and white dairy breed, which belong to the agricultural firm "Olimpex-Agro" (Dnipropetrovsk oblast). The level of stress in the cows' organism was defined according to concentration of cortisol and activity of creatine phosphokinase in the blood after experiencing stress before feeding in the morning. The stress factor was fixation of the animals, veterinary procedures and the process of taking blood for general planned analysis, and also occasions when the animals remained fixed for an hour without any opportunity to approach the feeder or drinking trough. Then they had their blood taken for measuring the concentration of cortisol and activity of creatine phosphokinase.

The method of defining the concentration of cortisol in the blood serum of the tested animals is based on the competition between untagged antigens and enzyme-tagged antigens for a particular number of bonds with antibodies. The number of enzyme-tagged antigens, bonded with antibodies is inversely proportional to the concentration of untagged antigens of the sample. We used reagents of Diagnostic system laboratory (USA), and also a micromonoclonal immunoenzymometric analyzer Stat Fax-2100, which was set for 450 and 600 or $620 \mathrm{~nm}$ wave length; incubator-shaker Stat Fax-2200, which was set for 500-700 movements a minute; automatic washer Stat Fax-2600; semi-automatic weighers for 5-50, 50-200 and 200$1000 \mu 1$. Optical density in cells was defined at the wave length of 450 and $620 \mathrm{~nm}$ (during 30 minutes after addition of stop-solution). Before collecting data on absorption, the device was set at " 0 " in correspondence to the zero standard (Blank). The values obtained for cortisol were used for plotting the standard curve for defining the concentration of cortisol in the studied blood samples. The samples with values higher than the highest standard were additionally dissolved by a standard $0 \mu \mathrm{g} / \mathrm{dl}$ and studied again. Because all results are given in $\mathrm{mcg} / \mathrm{dl}$, their conversion into $\mathrm{nmol} / \mathrm{l}$ was made by multiplying $\mu \mathrm{g} / \mathrm{dl}$ by 27.6 .

The method of identifying creatine phosphokinase was based on the fact that its activity is proportional to the amount of creatine which forms after fermentation. Creatine was identified by the staining reaction of $\alpha$-naphtol. We used the following equipment: spectrophotometer, volumetric flasks, thermostat, stopwatch. We used fresh blood with heparin without any hemolysis. The blood samples were transported to the laboratory as fast as possible. The serum was maintained in closed test tubes in the dark for two days at the temperature not higher than $+20 \ldots+25{ }^{\circ} \mathrm{C}$. The identification of creatine phosphokinase activity in the blood serum was made using a unified method with creatine as a substrate.

For studying the quality of colostrum, two separate groups were formed of animals with extreme values for reaction to stress. We used the method of pair-analogues by age in calving and body mass. All animals were daughters of the same male cow. The content of immunoglobulins in the first portions of colostrum was determined using the immunoenzymometric method with "Granum" set on the "Labline 32" device (Austria).

\section{Results and discussion}

The distribution of animals according to the concentration of cortisol in blood (Fig. 1a) 1 hour after the stress experience did not correspond to the norm. Therefore we divided animals into three groups.

Group 1 contained differentiated cows with concentration of cortisol in the blood within 19.9-112.8 nmol/l. They were conditionally referred to as "cows with high stress-resistance". Group II contained cows with concentration of cortisol in the blood within 112.8$205.7 \mathrm{nmol} / \mathrm{l}$ (modal class - "average stress - resistance"). Group III was composed of animals with the highest concentration of cortisol more than $205.7 \mathrm{nmol} / \mathrm{l}$ (conditionally named "low stress - resistance"). 

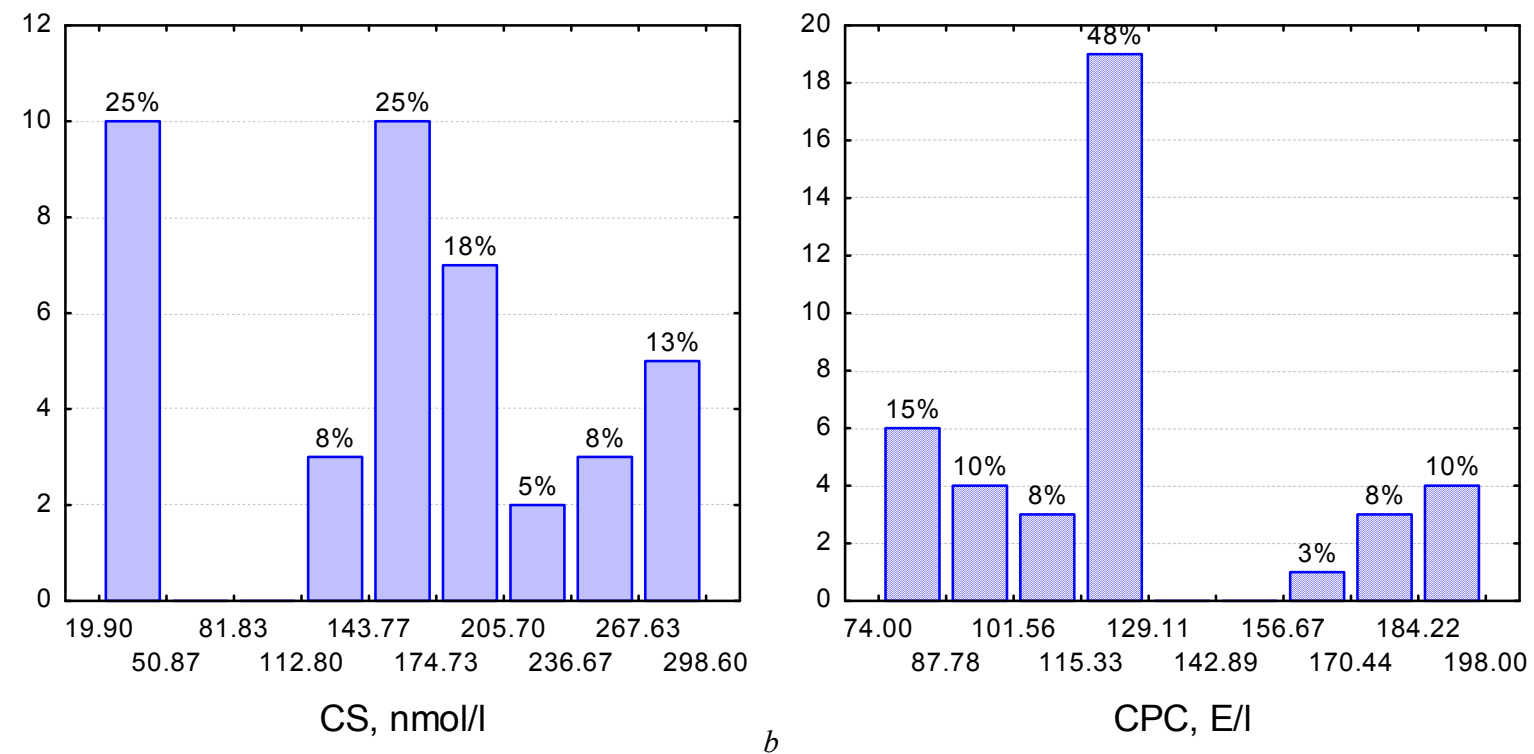

Fig. 1. Distribution of frequencies of variate values set in relation to cortisol $(a)$ and creatine phosphokinase $(b)$ 1 hour after the stress experience $(n=40)$

Concerning the activity of creatine phosphokinase, we observed clear asymmetry of distribution (Fig. 1b). Therefore this indicator was used only as an additional one. The peculiarities of animals' reaction to stress experience are presented in Fig. 2. The data presented shows that these groups of animals are quite different in their levels of reaction to stress.

While studying colostrum, we identified the classes of immunoglobulins: A, M, G and total protein (Fig. 3).

Classes of immunoglobulins $\mathrm{A}$ and $\mathrm{M}$ did not depend on $(\mathrm{P}>$ $0.05)$ which group the animals belonged to, whereas content of immunoglobulins of class $\mathrm{G}$ was higher by $6.7 \mathrm{~g} / 1(\mathrm{P}<0.05)$, and the content of total protein higher by $8.9 \mathrm{~g} / 1(\mathrm{P}<0.05)$ compared to portions of colostrum from the cows of the first group.

According to content of albumin and globulin fractions in the colostrum, no reliable differences between animals of the two extreme groups were found. However, we observed a clear tendency for their content to be higher in colostrum of cows from the first group.

We also studied the vitality of calves from cows with different reaction to stress, and also the vitality of mother-cows (Table).
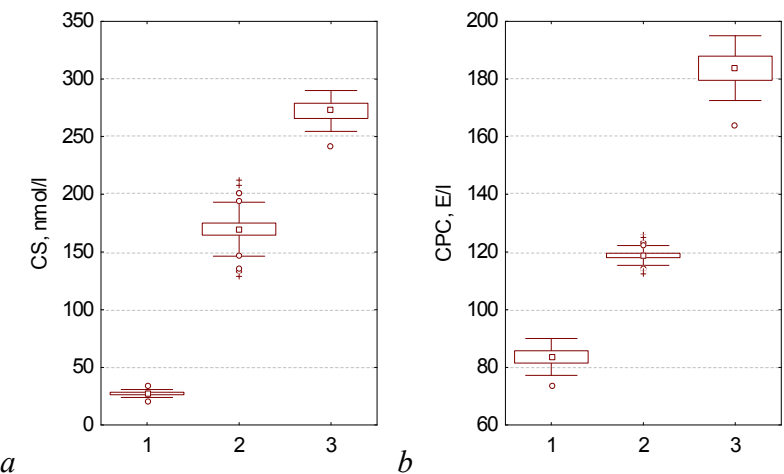

Fig. 2. Concentration of cortisol ( $a$ ) and activity of creatine phosphokinase $(b)$ in the blood of tested animals after stress:

1 - cows with high stress resistance $(\mathrm{n}=10) ; 2$ - with average stress resistance $(n=20) ; 3$ - with low stress resistance $(n=10)$;

Friedman ANOVA method

No abortions occurred in groups I and II, whereas a single case $(10 \%)$ occurred in group III. At the same time, groups I and III had cases of stillborn calves. No such cases occurred in group II. In most cases of loss of calves up to 6 months age, the cause of the death was gastroenteritis. This occurred more often among calves of cows from group III (30\%), compared to the first group (10\%).
There were no cases of other diseases found among calves from cows of group I. At the same time, catarrhal bronchopneumonia was observed among calves from cows of groups II (10\%) and III $(10 \%)$. There was one case $(10 \%)$ of general underdevelopment, which occurred in a calf from a cow of group III. Therefore only three calves (30\%) in group III survived after the age of 6 months. Out of 40 tested mother-cows, two cows from group III departed after the second calving.
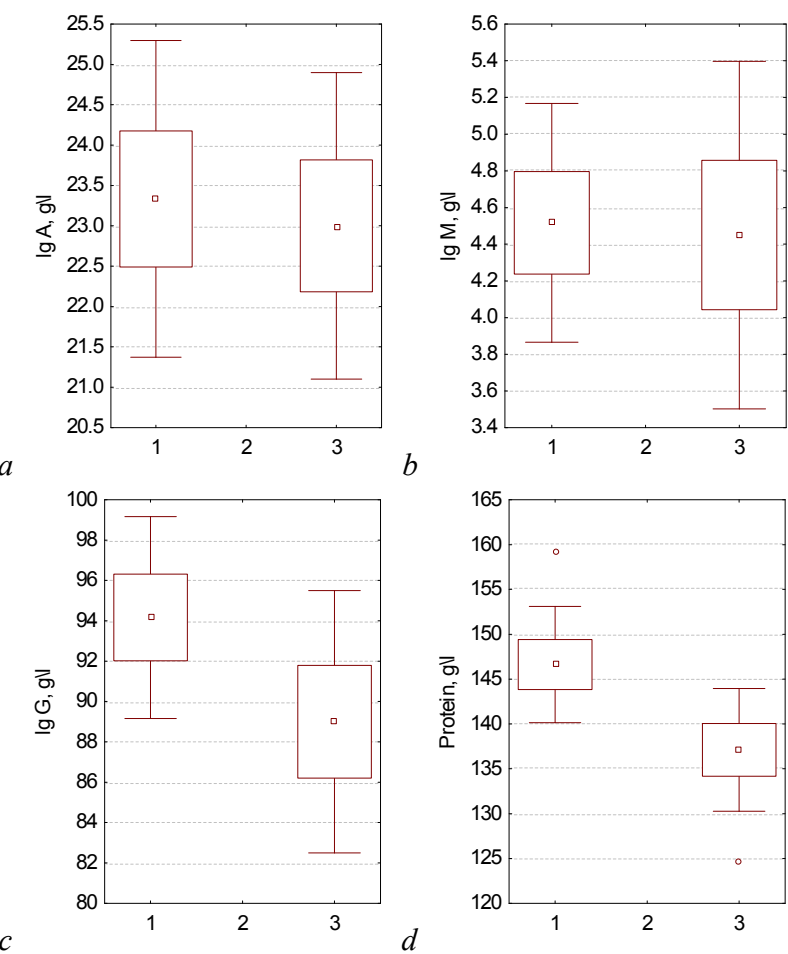

Fig. 3. Classes of immunoglobulin $(a, b, c)$ and total protein $(d)$ in colostrum of cows from two extreme groups: 1 - highly stress-resistant $(n=6) ; 3$ - low stress resistant $(n=6)$

\section{Conclusions}

The data obtained does not contradict the hypotheses that different levels of resistance to stress among mother-cows can directly or indirectly influence the quality of colostrum, particularly the content 
of immunoglubulins of class $\mathrm{G}$ and total protein, and also the vitality of their calves, and the vitality of mother-cows. At the same time, no
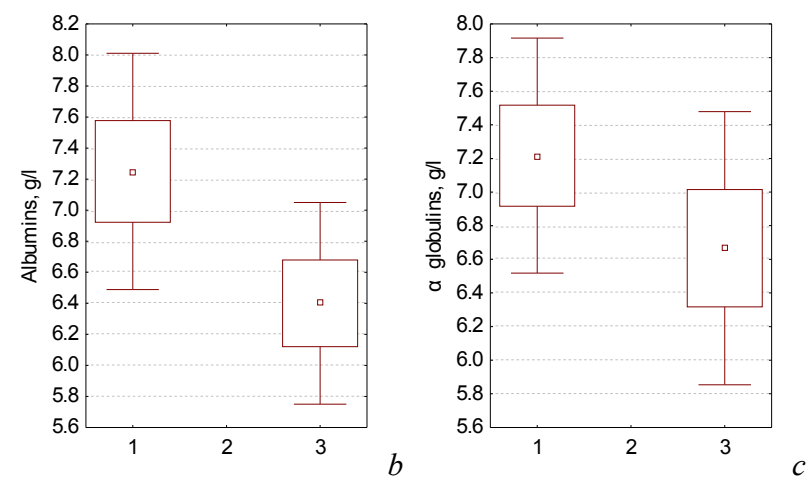

significant relationship between the cows' resistance to stress and abortions and stillborn calves was found.
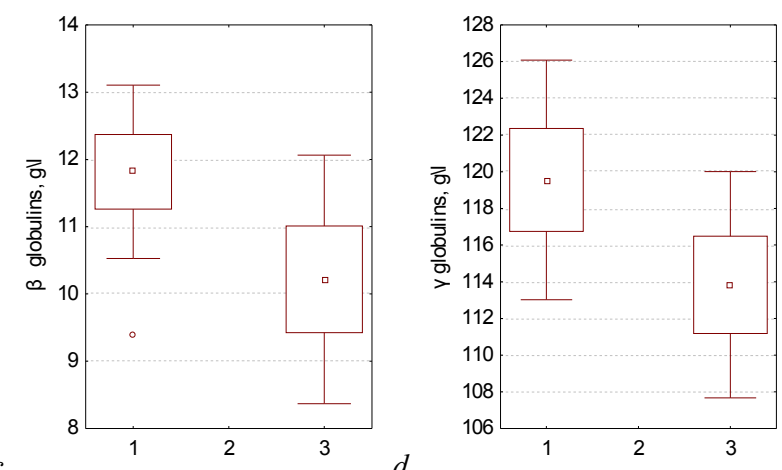

Fig. 4. Content of albumin $(a)$ and globulin fractions $(b, c, d)$ in colostrum of cows from two extreme groups: notation keys see Fig. 3

Table

Vitality of 6 month old calves from cows of different groups

\begin{tabular}{|c|c|c|c|c|c|c|c|c|}
\hline \multirow{3}{*}{ Indicator } & \multirow{2}{*}{\multicolumn{2}{|c|}{$\begin{array}{l}\text { Number of mother-cows, } \\
\qquad \mathrm{n}=40\end{array}$}} & \multicolumn{6}{|c|}{ Group of mother-cows } \\
\hline & & & \multicolumn{2}{|c|}{$\mathrm{I}, \mathrm{n}=10$} & \multicolumn{2}{|c|}{ II, $\mathrm{n}=20$} & \multicolumn{2}{|c|}{ III, $\mathrm{n}=10$} \\
\hline & head & $\%$ & head & $\%$ & head & $\%$ & head & $\%$ \\
\hline Abortion & 1 & 2.5 & - & - & - & - & 1 & 10.0 \\
\hline Stillborn & 2 & 5.0 & 1 & 10.0 & - & - & 1 & 10.0 \\
\hline catarrhal bronchopneumonia & 3 & 7.5 & - & - & 2 & 10.0 & 1 & 10.0 \\
\hline Causes gastroenteritis & 6 & 15.0 & 1 & 10.0 & 2 & 10.0 & 3 & 30.0 \\
\hline of cattle loss general underdevelopment & 1 & 2.5 & - & - & - & - & 1 & 10.0 \\
\hline Cows which departed after the second calving & 2 & 5.0 & - & - & - & - & 2 & 20.0 \\
\hline
\end{tabular}

Guaranteed provision of young calves with quality colostrum and adequate colostrum immunity in the conditions of constant technological stress is possible through regular control of the quality of colostrum quality using a special areometer (Colostrometer).

\section{References}

Azzam, S. M., Kinder, J. E., Nielsen, M. K., Werth, L. A., Gregory, K. E., Cundiff, L. V., \& Koch, R. M. (2017). Environmental effects on neonatal mortality of beef calves. Journal of Animal Science, 71(2), 282-290.

Beilharz, R. G., \& Zeeb, K. (1982). Social dominance in dairy cattle. Applied Animal Ethology, 8, 79-97.

Besser, T. E., Garmedia, A. E., McGuire, T. C., \& Gay, C. C. (1985). Effect of colostral immunoglobulin G1 and immunoglobulin M concentrations on immunoglobulin absorption in calves. Journal of Dairy Science, 68, 2033-2037.

Blum, J. W., \& Hammon, H. (2000). Colostrum effects on the gastrointestinal tract, and on nutritional, endocrine and metabolic parameters in neonatal calves. Livestock Production Science, 66(2), 151-159.

Borell, E., Dobson, H., \& Prunier, A. (2007). Stress, behaviour and reproductive performance in female cattle and pigs. Hormones and Behavior, 52(1), 130-138.

Borell, E., Langbein, J., Després, G., \& Hansen, S. (2007). Heart rate variability as a measure of autonomic regulation of cardiac activity for assessing stress and welfare in farm animals - a review. Physiology and Behavior, 92(3), 293-316.

Bush, L. J., \& Staley, T. E. (1980). Absorption of colostral immunoglobulins in newborn calves. Journal of Dairy Science, 63(4), 672-680.

Carroll, J. A., \& Forsberg, N. E. (2013). Influence of stress and nutrition on cattle immunity. Veterinary Clinics of North America: Food Animal Practice, 23(1), 105-149.

Chernenko, O. M. (2015a). The efficiency of the use of breeding servicing bulls based on their adaptive capacity. Science and Technology Bulletein of Scientific Research Center for Biosafety and Environmental Control of Agro-Industrial Complex, 3(1), 153-157 (in Ukrainian).

Chernenko, O. M. (2015b). Rezul'taty pleminnoho vykorystannya buhayivplidnykiv zalezhno vid yikh adaptatsiynoyi zdatnosti [Results of tribal use of bull-inseminators based on their adaptive capacity]. Tekhnolohiya Vyrobnytstva i Pererobky Produktsiyi Tvarynnytstva, 116, 88-91 (in Ukrainian).

Collier, R. J., Beede, D. K., Thatcher, W. W., Israel, L. A., \& Wilcox, C. J. (1982). Influences of environment and its modification on dairy animal health and production. Journal of Dairy Science, 65(11), 2213-2227.

Frank, J., \& Griffin, T. (1989). Stress and immunity: A unifying concept. Veterinary Immunology and Immunopathology, 20(3), 263-312.
Friend, T. H. (1980). Stress: What is it and how can it be quantified? International Journal for the Study of Animal Problems, 1(6), 366-374.

Friend, T. H., \& Polan, C. E., Gwazdauskas, F. C., \& Heald, C. W. (1977). Adrenal glucocorticoid response to exogenous adrenocorticotropin mediated by density and social disruption in lactating cows. Journal of Dairy Science, 60(12), 1958-1963.

Giesecke, W. H., \& Bigalke, R. D. (1985). The effect of stress on udder health of dairy cows. Onderstepoort Journal of Veterinary Research, 52, 175-193.

Gorewit, R. C., Svennersten, K., Butler, W. R., \& Uvnas-Moberg, K. (1992). Endocrine responses in cows milked by hand and machine. Journal of Dairy Science, 75(2), 443-448.

Hansen, P. J. (2002). Embryonic mortality in cattle from the embryo's perspective. Journal of Animal Science, 80(2), 33- 44.

Hansen, P. J., \& Arechiga, C. F. (1998). Strategies for managing reproduction in the heat-stressed dairy cow. Journal of Animal Science, 77, 36-50.

Hickey, M. C., Drennan, M., \& Earley, B. (2002). The effect of abrupt weaning of suckler calves on the plasma concentrations of cortisol, catecholamines, leukocytes, acute-phase proteins and in vitro interferongamma production. Journal of Animal Science, 81(11), 2847-2855.

Igono, M. O., \& Johnson, H. D. (2008). Physiologic stress index of lactating dairy cows based on diurnal pattern of rectal temperature. Journal of Interdisiplinary Cycle Research, 21(4), 303-320.

Lacetera, N., Bernabucci, U., Ronchi, B., Scalia, D., \& Nardone, A. (2001). Moderate summer heat stress does not modify immunological parameters of Holstein dairy cows. International Journal of Biometeorology, 46(1), 33-37.

Lefcourt, A. M., \& Akers, R. M. (1982). Endocrine responses of cows subjected to controlled voltages during milking. Journal of Dairy Science, 65(11), 2125-2130.

Maunsell, F. P, Morin, D. E., Constable, P. D., Hurley, W. L., Maunsell, F. P., McGoy, G. C., Kakoma, I., \& Isaacson, R. E. (1998). Effects of mastitis on the volume and composition of colostrum produced by Holstein cows. Journal of Dairy Science, 81, 1291-1299.

Merlot, E., Quesnel, H., \& Prunier, A. (2013). Prenatal stress, immunity and neonatal health in farm animal species. Animal, 7(12), 2016-2025.

Moberg, G. P., \& Mench, J. A. (2000). The biology of animal stress: Basic principles and implications for animal. University of California, CABI Publishing, New York, 111-118.

Monty, D. E., \& Racowsky, C. (1987). In vitro evaluation of early embryo viability and development in summer heat-stressed, superovulated dairy cows. Theriogenology, 28(4), 451-465.

Morin, D. E., Constable, P. D., Maunsell, F. P., \& McGoy, G. C. (2001). Factors associated with colostral specific gravity in dairy cows. Journal of Dairy Science, 84(4), 937-943. 
Muller, L. D., \& Ellinger, D. K. (1981). Colostral immunoglobulin concentrations among breeds of dairy cattle. Journal of Dairy Science, 64(8), 1727-1730.

Nardone, A., Lacetera, N., Bernabucci, U., \& Ronch, B. (1997). Composition of colostrum from dairy heifers exposed to high air temperatures during late pregnancy and the early postpartum period1. Journal of Dairy Science, 80(3), 838-844.

Pakkanen, R., \& Aalto, J. (1997). Growth factors and antimicrobial factors of bovine colostrum. International Dairy Journal, 7(5), 285-297.

Robison, J. D., Stott, G. H., \& DeNise, S. K. (1988). Effects of passive immunity on growth and survival in the dairy heifer. Journal of Dairy Science, 71(5), $1283-1287$.

Roth, J. A. (1985). Cortisol as mediator of stress-associated immunosuppression in cattle. In: G. P. Moberg (ed.) Animal Stress. Springer, New York, pp. 225-243.

Salak-Johnson, J. L., \& McGlone, J. J. (2006). Making sense of apparently conflicting data: Stress and immunity in swine and cattle. Journal of Animal Science. 85(13), 81-88.
Tao, S., Monteiro, A. P. A., Thompson, I. M., Hayen, M. J., \& Dahl, G. E. (2012). Effect of late-gestation maternal heat stress on growth and immune function of dairy calves. Journal of Dairy Science, 95(12), 7128-7136.

Tenhagen, B. A., Helmbold, A., \& Heuwieser, W. (2007). Effect of various degrees of dystocia in dairy cattle on calf viability, milk production, fertility and culling. Journal of Veterinary Medicine. A, Physiology Pathology, Clinical Medicine, 54(2), 98-102.

Wenzel, C., Schönreiter-Fischer, S., \& Unshelm, J. (2003). Studies on stepkick behavior and stress of cows during milking in an automatic milking system. Livestock Production Science, 83, 237-246.

Wolfenson, D., Roth, Z., \& Meidan, R. (2000). Impaired reproduction in heat-stressed cattle: Basic and applied aspects. Animal Reproduction Science, 60(2), 535-547. 